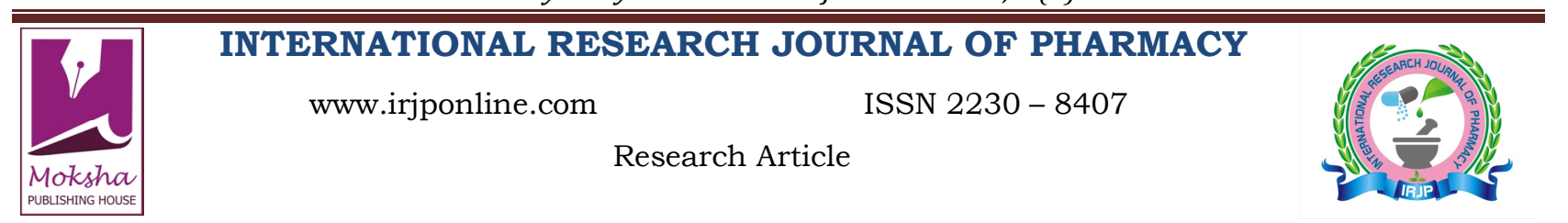

\title{
COMPARISON OF DEMINERALIZING EFFECT OF COMMERCIAL EDTA PREPARATIONS AT DIFFERENT TIME INTERVALS BASED ON MEASUREMENT OF THE AMOUNT OF PHOSPHORUS RELEASED FROM HYDROXYAPATITE
}

\author{
Shetty Aditya, Hegde Mithra N, Mathew Tony*, Bhat Ganesh \\ Department of Conservative Dentistry and Endodontics, AB Shetty Memorial Institute of Dental Sciences, NITTE University, \\ Mangalore, Karnataka, India \\ *Corresponding Author Email: dr.tonymathew@gmail.com
}

Article Received on: 20/08/13 Revised on: 19/09/13 Approved for publication: 17/09/13

DOI: $10.7897 / 2230-8407.04927$

IRJP is an official publication of Moksha Publishing House. Website: www.mokshaph.com

(C) All rights reserved.

\section{ABSTRACT}

The objective of this in-vitro study is to compare the de mineralizing effect of commercial EDTA in different concentrations and different time intervals with respect to the amount of phosphorus released from hydroxyapatite. 96 freshly extracted maxillary central incisor roots were randomly grouped 4 groups of 24 specimens each. The first group, the control group was treated with saline. The second group was treated with a commercial preparation of EDTA- RC PREP. The third group was treated with a commercial preparation of EDTA- Glyde and the fourth group was treated with a solution of $17 \%$ EDTA. All the groups were treated with the respective formulations for time intervals one, three, ten and fifteen minutes each. The solutions obtained from each of the four groups were analyzed for phosphorus content using colorimetric analysis. Group II i.e. R C Prep showed the highest de mineralizing effect for 1 , 3 and 10 minutes respectively. Group III i.e. Glyde showed the highest de mineralizing effect for 15 minutes. Among the solutions containing EDTA, Group IV i.e. $17 \%$ EDTA solution showed the least de mineralizing effect, despite the higher concentration. This is because of the additives present in commercially available chelating pastes.

Keywords: EDTA, RC-PREP, Glyde, hydoxyapatite, Phosphorus

\section{INTRODUCTION}

A chemical substance facilitating the instrumentation of the root canal EDTA (Ethylene Diamine Tetra Acetic acid) is generally accepted as the most effective chelating agent in endodontic therapy. It is used to enlarge root canals, remove smear layer and prepare the dentinal walls for better adhesion of filling materials. The efficiency of chelating agents generally depends on many factors, such as root canal length, penetration depth of the material, hardness of the dentin, duration of application and the concentration. Chelating agents were introduced into endodontics as an aid for the preparation of narrow and calcified root canals in 1957 by Nygaard-Ostby ${ }^{1}$. A liquid solution of EDTA was thought to chemically soften the root canal dentin and dissolve the smear layer, as well as to increase dentin permeability. Although the efficacy of EDTA preparations in softening root dentin has been debated, chelator preparations have regained popularity recently. Almost all manufacturers of nickeltitanium instruments recommend their use as a lubricant during rotary root canal preparation. Additionally, a final irrigation of the root canal with $15-17 \%$ EDTA solutions to dissolve the smear layer is recommended. The term 'chelate' originates from the Greek word 'chele' (crab claw). Chelates are particularly stable compounds of metal ions with organic substances, as a result of ring shaped bonds. This stability is a result of the bond between the chelator, which has more than one pair of electrons, and the central metal ion. In 1951, the first reports on the de mineralizing effect of ethylene diamine tetraacetic acid (EDTA) on dental hard tissues were published (Hahn and Reygadas 1951, Screebny and Nikiforuk 1951) ${ }^{1}$. The purpose of the study was to compare the effects of EDTA on dentin de mineralization by measuring the amount of liberated phosphorous from the hydroxyapatite. The level of de mineralization measuring the amount of liberated phosphorus has not been investigated with respect to commercial EDTA preparations hence the need for the study. EDTA effectively de mineralizes dentin depending on the concentration and the time of exposure ${ }^{2}$. The amount of phosphorus released from the hydroxyapatite is used as a measure to determine the amount of dentin de mineralization.

\section{MATERIALS AND METHODS}

\begin{tabular}{|c|c|c|}
\hline Products & Composition & Use \\
\hline GLYDE & $\begin{array}{c}\text { EDTA and Urea peroxide with } \\
\text { Dentsply }\end{array}$ & $\begin{array}{c}\text { Chelating } \\
\text { agent }\end{array}$ \\
\hline $\begin{array}{c}\text { RC PREP } \\
\text { Premier }\end{array}$ & $\begin{array}{c}\text { EDTA and Carbamide peroxide } \\
\text { with a glycol base. }\end{array}$ & $\begin{array}{c}\text { Chelating } \\
\text { agent. }\end{array}$ \\
\hline & EDTA & $\begin{array}{c}\text { Chelating } \\
\text { agent. }\end{array}$ \\
\hline
\end{tabular}

The present study was done in the department of Conservative Dentistry and Endodontics, A.B. Shetty Memorial Institute of Dental Sciences, Deralakatte, Mangalore, India in association with K. S. Hegde Medical Academy. Ninety six freshly extracted human maxillary central incisor roots were collected, stored, disinfected and handled as per the recommendation and the guidelines lay down by OSHA and CDC. The specimen teeth were collected from the Department of Oral and Maxillofacial Surgery, A.B. Shetty Memorial Institute of Dental Sciences, Deralakatte, Mangalore, India. All the collected teeth were cleared of blood and saliva and stored in buffered isotonic saline solution. These specimen teeth were utilized for this study within one month of extraction. Infection Control Protocols were followed for Extracted Teeth.

\section{Investigation Design}

Ninety six freshly extracted maxillary central incisor roots were randomly grouped in to one control group containing 24 specimens and three experimental groups each containing 24 specimens. Each group was further divided in to 4 subgroups. SUB Group a - Treated for 1 minute 
SUB Group $b$ - Treated for 3 minutes

SUB Group c - Treated for 10 minutes

SUB Group d - Treated for 15 minutes

The maxillary central incisor roots were split longitudinally, to expose the root canal surface using a diamond disc. Each specimen was then coated with nail varnish on the outer surface so that the solution to be tested would affect only the root canal space. The first group, the control group consisting of twenty four specimens was treated with saline for duration of one, three, ten and fifteen minutes respectively, with six specimens in each time interval. The second group, consisting of twenty four specimens was treated with a commercial preparation of EDTA, RC PREP (15\% EDTA and $10 \%$ urea peroxide in propylene glycol) for one, three, ten and fifteen minutes respectively, with six specimens in each time interval. The third group, consisting of twenty four specimens was treated with a commercial preparation of EDTA, GLYDE (15\% EDTA and $10 \%$ urea peroxide in aqueous solution) for one, three, ten and fifteen minutes respectively, with six specimens in each time interval. The fourth group, consisting of twenty four specimens was treated with a solution of $17 \%$ EDTA, prepared from dissolving 15 g EDTA powder in $100 \mathrm{ml}$ of distilled water. For one, three, ten and fifteen minutes respectively, with six specimens in each time interval. The solutions obtained from each of the four groups with their corresponding sub groups after exposure of the specimens to the EDTA solution, were analyzed for phosphorus using colorimetric analysis. The Phosphorus Content was analyzed using the following formula-

$$
\begin{aligned}
& \mathrm{Mg} / \mathrm{dl} \text { of Inorganic phosphorus= } \\
& \text { Optical density of test soln X Conc.of standard soln X } 100 \\
& \text { Optical density of std. soln Vol. of test soln }
\end{aligned}
$$

The results thus obtained were statistically analyzed.

\section{RESULTS}

The de mineralizing effect of commercial EDTA preparations in different concentrations and different time intervals with respect to the amount of phosphorus released showed that EDTA effectively de materializes dentin depending on the concentration and time of exposure. In all three experimental groups there was increase in de mineralization with increase in time. Group II and III showed significant increase in phosphorus content with increase in time. Group II and III showed nearly double the efficiency of de mineralization when the time of exposure was increased from 1 minute to 15 minutes. The control group did not show any de mineralizing effect at any time interval. The statistical analysis of the mean values showed that: Comparison was done using Analysis of Variance between Group I, II, III and IV showed very highly significant difference ( $\mathrm{p}>.001)$, after 1 minute, 3 minutes, 10 minutes and 15 minutes. Inter group comparison was done using Man Whitney U test between Group II, Group III and group IV showed very highly significant difference $(\mathrm{p}>.001)$. Group II i.e. R C Prep showed the highest de mineralizing effect for 1 minute, 3 minutes and 10 minutes respectively. Group III i.e. Glyde showed the highest de mineralizing effect for 15 minutes. Among the solutions containing EDTA Group IV i.e. EDTA Solution showed the least de mineralizing effect. Group II and Group III showed significant increase in de mineralization with increase in time of exposure, Group IV showed no significant increase in de mineralization with respect to time. Group I which was Saline as the Negative Control showed absolutely no de mineralization in all the time intervals.

\section{DISCUSSION}

Since the combination of Cetavlon and EDTA by Vonderfehr and Nygaard Ostby in $1963^{\circ}$ many additives have been introduced into EDTA. It was the Aim of the present investigation to compare two commercially available chelating pastes (with different compositions) with $17 \%$ EDTA solution. Curry et al $(1981)^{3}$ concluded in their study that the greatest efficiency of de mineralization by EDTA could be achieved with the pH ranging between 5 to 6 . Similar results have been reported by Serper and Calt $(2002)^{8}$ who stated that EDTA should be preferred at a neutral $\mathrm{pH}$. That is why $\mathrm{pH}$ has been taken as a constant in this study. Serper and Calt $(2002)^{4}$, Johan blomlof et al $(1997)^{4}$,Garberoglio R. et al $(1994)^{11}$ reported that concentration of EDTA should be between 15 to $24 \%$ In order to obtain an acceptable smear removing and collagen exposing effect within a clinically accepted time period. Hence in the study we have used $17 \%$ EDTA solution in Group IV, while the commercial chelating pastes used had the $15 \%$ concentration of EDTA. For effective removal of both organic and inorganic component of smear layer, it is generally recommended to use EDTA followed by $\mathrm{NaOCl}$. In the present study we have compared the de mineralizing effect of commercial EDTA preparations at different time intervals along with the prepared solution of $17 \%$ EDTA. Similar to the study done by Jaime A. Cury $(1981)^{3}$ et al who studied the de mineralizing effect of EDTA on dentin by analyzing the Phosphorus content using colorimetric analysis in a spectrophotometer

The results of the present study indicate increase decalcification which was significantly related to the contact period between chelator paste and dentin as reported by previous investigators Hullsman et al 2002 $2^{7}$, Goldberg and Spielberg $1982^{12}$, Semra and Calt $2002^{4}$ which is in accordance with the results of this study where significant difference in de mineralization by the chelator pastes Group II and Group III were seen for 1, 3, 10, and 15 minutes time intervals. However the EDTA solution showed a significant difference in de mineralization between 1 and 15 minutes only, as compared to the chelating pastes. Phosphorus content was analyzed using colorimetric analysis in a spectrophotometer Jaime A. Cury (1981) ${ }^{3}$. Comparison using analysis of variance was done between Group II, Group III and Group IV. Group I was control that is saline. Results of the study showed that Group II which contained $15 \%$ EDTA, $10 \%$ Urea peroxide in a water soluble gel base, polyethylene glycol, cetylalcohol, propyleneglycol had the highest de mineralizing effect for 1,3 and 10 minutes. While Group III which contained $15 \%$ EDTA, $10 \%$ Urea Peroxide in an aqueous solution showed maximum de mineralizing effect for 15 minutes. Very highly significant differences were found between the 2 EDTA pastes and the EDTA solution. These results are in contrast to the results of the previous study by Hulsemann et al $20^{7}$, which showed no significant differences in decalcification between RC Prep and Glyde. These differences to the previous study presumably are owing to the fact that Hulsmann ${ }^{5}$ et al measured the loss of weight from the specimens; while in the present study the released phosphorus content was estimated to determine demineralization similar to the study done by Serper and Calt $(2002)^{8}$, Jaime A Cury et al $(1981)^{3}$. 


\begin{tabular}{|c|c|c|c|c|}
\hline Sub Groups & Saline & R C Prep & Glyde & EDTA Soln. \\
\hline a-1 minute & 0 & 5.6 & 4.2 & 1.1 \\
\hline b-3 minutes & 0 & 7.7 & 6.0 & 1.2 \\
\hline c-10 minutes & 0 & 8.5 & 8.4 & 1.3 \\
\hline d-15 minutes & 0 & 8.9 & 9.9 & 1.3 \\
\hline
\end{tabular}

Table 2: Comparison using Analysis of Variance between Group I, II, III and IV

\begin{tabular}{|c|c|c|c|c|c|c|c|}
\hline & \multirow[t]{2}{*}{$\mathbf{N}$} & \multirow[t]{2}{*}{ Mean } & \multirow{2}{*}{$\begin{array}{c}\text { Std. } \\
\text { Deviation }\end{array}$} & \multicolumn{2}{|c|}{$\mathbf{9 5 \%}$ confidence interval for Mean } & \multirow[t]{2}{*}{$\mathbf{F}$} & \multirow[t]{2}{*}{$\mathbf{P}$} \\
\hline & & & & Lower bound & Upper bound & & \\
\hline Minute 1: $\mathrm{RC}$ prep & 6 & 5.8000 & $8.944 \mathrm{E}-02$ & 5.7061 & 5.8939 & 1379.250 & $.001 \mathrm{vhs}$ \\
\hline Glyde 4.2 & 6 & 4.8000 & .1897 & 4.6009 & 4.9991 & & \\
\hline EDTA solution & 6 & 1.1000 & .1897 & .9009 & 1.2991 & & \\
\hline Minutes 3: RC prep & 6 & 7.7000 & .1414 & 7.5516 & 7.8484 & 2691.316 & $.001 \mathrm{vhs}$ \\
\hline Glyde 4.2 & 6 & 6.6000 & .2000 & 5.7901 & 6.2099 & & \\
\hline EDTA solution & 6 & 1.2000 & .1265 & 1.0673 & 1.3327 & & \\
\hline Minutes 10: RC prep & 6 & 8.5000 & .2608 & 8.2263 & 8.7737 & 2018.289 & $.001 \mathrm{vhs}$ \\
\hline Glyde 4.2 & 6 & 8.4000 & .1414 & 8.2516 & 8.5484 & & \\
\hline EDTA solution & 6 & 1.3000 & .2530 & 1.0345 & 1.5655 & & \\
\hline Minutes 15: RC prep & 6 & 8.9000 & .2828 & 8.6032 & 9.1968 & 4147.500 & $.001 \mathrm{vhs}$ \\
\hline Glyde 4.2 & 6 & 9.9000 & .1265 & 9.7673 & 10.0327 & & \\
\hline EDTA solution & 6 & 1.3000 & $3.394 \mathrm{E}-17$ & 1.3000 & 1.3000 & & \\
\hline
\end{tabular}

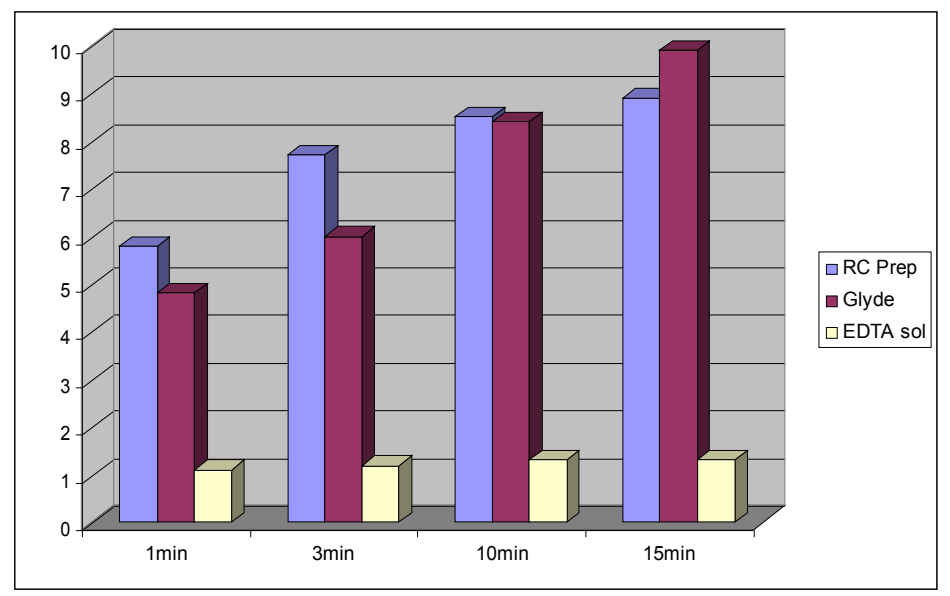

Graph: Mean Phosphorus content among various Groups and Sub-Groups with Respect to time

In this study we have compared the de mineralizing effect of EDTA on root dentin, at different concentrations at different intervals of time; our results showed that higher the duration of application of EDTA greater the demineralizing effect on root dentin, $15 \%$ EDTA with additives available as commercial preparations had greater de mineralization than $17 \%$ EDTA solution. However before we conclude the limitation of our present study was that the chronological age of the teeth specimens were not documented and to minimize erosive effects precautions must be taken when EDTA is used clinically on young patients, the application time should be as short as possible compared to the older patients who have more sclerotic dentin in the apical and middle third. It is highly recommended that under clinical conditions EDTA and $\mathrm{NaOCl}$ should be used in combination because of the progressive dissolution of dentin at the expense of peritubular and inter-tubular dentin by EDTA and $\mathrm{NaOCl}$ which acts as an organic solvent ${ }^{13}$.

\section{CONCLUSION}

According to the methodology employed in the present study it can be concluded that: The efficiency of EDTA solutions on the de mineralization of dentin is influenced by time of exposure. The greatest amount of de mineralization was achieved at 15 minutes. Even though the concentration of
EDTA (17\%) in Group IV was comparatively more, both the commercial chelating pastes (EDTA $15 \%$ ) showed higher de mineralizing effects because of the additives present in commercially available chelating pastes. The present the study is an in-vitro evaluation where a large quantity of the chelating agent was in contact with the root surface. Clinically factors such as root canal size, length, diameter, combination of irrigate used, type of irrigation technique, and ages of the teeth are the factors which may modify the de mineralizing effect.

\section{REFERENCES}

1. M Hulsmann, M Heckendrof and A Lennon. Chelating agents in root canal treatment mode of action and indications for their use. Int Endod J 2003; 36: 810-830. http://dx.doi.org/10.1111/j.1365-2591.2003.00754.x

2. Semra Calt and Ahmet Serper. Time dependent effects of EDTA on dentin structures.Journal of Endodontics 2002; 28(1): 17-19. http://dx.doi.org/10.1097/00004770-200201000-00004 PMid:11806642

3. Jaime A Cury, Claudio Bragotto and Luiz Valdrighi. The de mineralizing efficiency of EDTA solutions on dentin. Oral surgery, Oral pathology, Oral medicine 1981; 52: 446-8.

4. LF Machado Silveiro, S Gonzalez lopez and MP Gonzalez Rodriguez. Decalcification of root canal dentin by citric acid, EDTA and sodium citrate Int Endod J 2004; 37: 365-369. http://dx.doi.org/10.1111/j.13652591.2004.00813.x PMid: 15186242

5. Perez VC, Cardenas MEM. Planells: The possible role of $\mathrm{pH}$ changes during EDTA demineralization of teeth Oral surg oral med oral pathol 1989; 68: 220-2. http://dx.doi.org/10.1016/0030-4220(89)90196-5 
6. Takakazu Yoshida, Taiji Shibata, Tomimi Shinohara, Shunji Gomyo and Ichiro Sekine. Clinical evaluation of the efficacy of EDTA solution as an endodontic irrigant. Journal of Endodontics 1995; 21(12). http:// dx.doi.org/10.1016/S0099-2399(06)81109-X

7. Johan Blomlof, Leif Blomlof and Sven Lindskog. Effect of different concentrations of EDTA on smear removal and collagen exposure in periodontitis effected root surfaces. J Clin Periodontol 1997; 24: 534-537. http://dx.doi.org/10.1111/j.1600-051X.1997.tb00225.x PMid:9266339

8. George G Stewart. A scanning electron microscopy of the cleansing effectiveness of three irrigating modalities on the tubular structure of dentin. Journal of Endodontics 1998; 24(7).

9. Steinberg DD, Abid El Raziq and Heling I. In vitro antibacterial effect of RC-Prep components on Streptococcus sobrinus. Endod Dent
Traumatol 1999; 15: 171-174. http://dx.doi.org/10.1111/j.16009657.1999.tb00796.x PMid: 10815566

10. Verdelis K, G Eliades, T Ovlir, J Marglos. Effect of chelating agents on the molecular composition and extent of decalcification at cervical, middle and apical root dentin locations. Endod Dent Traumatol 1999; 15: 164-170. http://dx.doi.org/10.1111/j.1600-9657.1999.tb00795.x PMid: 10815565

11. Cynthia T Tatsuta et al Journal of Endodontics 1999; 25(2).

Cite this article as:

Shetty Aditya, Hegde Mithra N, Mathew Tony, Bhat Ganesh. Comparison of demineralizing effect of commercial EDTA preparations at different time intervals based on measurement of the amount of phosphorus released from Hydroxyapatite. Int. Res. J. Pharm. 2013; 4(9):128-131 http://dx.doi.org/ $\underline{10.7897 / 2230-8407.04927}$

Source of support: Nil, Conflict of interest: None Declared 